\title{
Lumbar Epidural Analgesia as a New Paradigm: Views of Women in Rural and Urban Community in Yogyakarta
}

\author{
Iman Permana ${ }^{1}$, Supriyatiningsih ${ }^{2}$, Pramitha Esha Nirmala Dewi ${ }^{3}$
}

\author{
${ }^{1}$ Master of Nursing, Universitas Muhammadiyah Yogyakarta, Indonesia \\ ${ }^{2}$ Department of Obstetrics and Gynaecology, Faculty of Medicine and Health Sciences, Universitas Muhammadiyah \\ Yogyakarta, Indonesia \\ ${ }^{3}$ Department of Pharmacy, Faculty of Medicine and Health Sciences, Universitas Muhammadiyah Yogyakarta \\ Yogyakarta, Indonesia \\ *Corresponding Author.Email: imanpermana@umy.ac.id
}

\begin{abstract}
Pain in labor has been problematic for women regardless their socio-economic status. Lumbar Epidural Analgesia (LEA) was suggested to provide high-quality pain relief and minimizing side-effects both for maternal and the fetus or on the outcome of labour. The aim of this study was to explore the awareness and acceptance of lumbar epidural analgesia' procedure among pregnant women. This study was a descriptive analytic using questionnaire. Eighty women consisted of 40 from rural and 40 from urban areas who planned to have delivery process at Asri Medical Center, Yogyakarta. Majority of the respondents in both group $50(66,75 \%)$ were not aware of epidural analgesia. Of the $25(33,25 \%)$ who were aware, 12 knew it was used to relieve pain in labor and 13 had first knowledge about epidural analgesia from doctors and midwife at hospital. A majority of the respondents $65(86,66 \%$ ) would accept epidural analgesia. The age of pregnant women, level of education, social economic status and number of gravida were statistically significant, except for gestational age. Both groups also have expectations to have no pain delivery process $(\mathrm{p}=0.001$ and $\mathrm{p}=0,002)$. Most of the participants has not been acknowledged adequately to LEA. Nevertheless, majority of participants accept it as an option of mean of pain relief.
\end{abstract}

Keywords: Lumbar Epidural Analgesia, New Paradigm, Views of Women in Rural and Urban Community

\section{INTRODUCTION}

Pain during labor process has been considered to be the significant issue among pregnant mother; it is involving not only physiological aspect but also psychological [1]. Moreover, the perception on the pain was influenced by several factors such as culture and the number of deliveries, to mention some of them. Some women in some cultures believed that pain in labor is a natural sensation and inevitable, thus, the ability to accept and endure it is regarded as a normal condition that come in due process [2]. Nevertheless, for most of the women the existence of the pain during labor was considered painful, even after the administration of childbirth training [3].

Apart from the traditional medicine-free approach, the utilization of analgesic and aesthetics have also been introduced. The aim of the pain relief procedure is to minimize the pain to the level in which the pregnant mother is still able to actively participate in the labor process [1]. Pharmacological measures vary from inhalational measure, parenteral opioid, and regional analgesia. The later procedure consists of epidural, combined spinal epidural (CSE) and continuous spinal analgesia (CSA).

It is argued that with the correct dosage of anesthetical drug and the precise timing, the procedure of epidural analgesia will not hamper the consciousness level of the mother and maintaining the mother to be actively engaged in the process of delivery [4]. Furthermore, the use of low concentrations of local anaesthetics, combined with lipid-soluble opioids, does not impede the progress of labor or depress the new-born [5].

Epidural analgesia is an extremely effective and popular treatment for labor pain. In the US the administration of this procedure had been tripled between 1981 to 2001 [6]. Similar trend had also been witnessed in Canada with the varies number of $30 \%$ to $69 \%$ across the country between 2006 to 2011[7]. Despite of the advantages provided, LEA has not been fully accepted and is not routinely practised in most of the delivery centres in Indonesia [8]. The aim of this study was to explore the views of pregnant women in awareness and the acceptance LEA as pain reliever during labor who attending antenatal clinic of our hospital who are coming from rural and urban area.

\section{METHODOLOGY}

Following institutional ethics committee approval, 80 pregnant women were included in this crosssectional study attending antenatal care in Asri Medical Center from January to June 2018. They were interviewed using a questionnaire that determined their perception of pain labor and expectations regarding labour analgesia technique. The questionnaire was prepared after discussion among the authors and referring to previous studies $[9,10]$. The questionnaire was prepared in 
Bahasa Indonesia. Confidentiality of the participants was maintained by replacing their identity to codes. Eighty respondents were counselled regarding to the adoption of lumbal epidural analgesia as painless labour and opted for epidural analgesia. Primary outcome measure were demographics, and secondary outcome measures was awareness about Labor Epidural Analgesia (LEA), willingness for LEA after giving complete information to them. Inclusion criteria were healthy patients with cephalic presentation, singleton pregnancy and 37-42 weeks gestation. Patients were included only after an informed consent was obtained. The exclusion criteria are women with any confounding condition such as hypertension disorders, diabetes, preterm labor, bleeding disorders, scoliosis, allergy to study drug, blood in CSF in epidural catheter.

Students t test and chi-square was utilized to analyze the difference of perception between urban and rural groups.

\section{RESULT AND DISCUSSION}

Table 1 shows the demographic characteristics of the respondents of the study with eighty respondents $(100 \%)$ completed the questionnaires.

TABEL 1. SOCIO DEMOGRAPHIC CHARACTERISTICS OF RESPONDENTS OF PREGNANT WOMEN FROM RURAL AND URBAN AREAS

\begin{tabular}{|c|c|c|c|c|c|c|}
\hline \multirow{2}{*}{ No } & \multirow{2}{*}{ Characteristics } & \multicolumn{2}{|c|}{ Rural } & \multicolumn{2}{|c|}{ Urban } & \multirow{2}{*}{$\mathrm{P}$} \\
\hline & & $\mathrm{N}$ & $\%$ & $\mathrm{~N}$ & $\%$ & \\
\hline \multirow[t]{4}{*}{1.} & Age Group & & & & & \\
\hline & $18-22$ & 15 & 37.5 & 4 & 10 & \multirow{3}{*}{$0.001 *$} \\
\hline & $23-35$ & 20 & 50 & 30 & 75 & \\
\hline & $>35$ & 5 & 12.5 & 6 & 15 & \\
\hline \multirow[t]{3}{*}{2.} & Gestational age & & & & & \\
\hline & $37-40$ & 25 & 62.5 & 35 & 87.5 & \multirow{2}{*}{0,080} \\
\hline & $>40$ & 15 & 37.5 & 5 & 12.5 & \\
\hline \multirow[t]{4}{*}{3.} & Socio economic status & & & & & \\
\hline & Low & 25 & 62.5 & 5 & 12.5 & \multirow{3}{*}{$0.002 *$} \\
\hline & Middle & 10 & 25 & 10 & 25 & \\
\hline & High & 5 & 12.5 & 25 & 62.5 & \\
\hline \multirow[t]{4}{*}{4.} & Educational Status & & & & & \\
\hline & Elementary school & 15 & 37.5 & 4 & 10 & \multirow{3}{*}{$0.012 *$} \\
\hline & High shool & 15 & 37.5 & 11 & 27.5 & \\
\hline & Graduate & 10 & 25 & 25 & 62.5 & \\
\hline \multirow[t]{3}{*}{5.} & Gravida & & & & & \\
\hline & Primigravida & 25 & 62.5 & 30 & 75 & \multirow{2}{*}{$0.020 *$} \\
\hline & Multigravida & 15 & 37.5 & 10 & 25 & \\
\hline
\end{tabular}

The majority of patients belonged to the age group of 2335 years old with $50 \%$ in rural group and $75 \%$ in urban group and were primigravida. This age group is the age of maximum reproducibility and this result was equal with the study of Sheiner et al [11] and Gupta et al [12]. The mayority number of patients belonged to 37-40 weeks of gestation in both the groups. The majority of the patients belonged to low socioeconomic status $(62.5 \%)$ in rural group in contradictory to the higher level of socioeconomic which share approximately the same figure in the urban group. The educated patients opted more for epidural analgesia. Above mentioned socio demographic factors were compared between the two groups, but there was no statistically significant difference was found. Statistical test was done to determine the difference between the two groups in regard to each characteristic. Except for the gestational age, all characteristics are significantly different with the $\mathrm{p}$ value less than 0.05 .

Our study further shows distribution according to age of pregnant women, educational status, socio economic level, number of gravida (primi or multigravida) have significantly associated with the new paradigm of using the LEA in both groups, this was partially supported by the study of Morr AK et al [13] who found a significant difference in the utilization of epidural analgesia in women with a higher educational degree.

TABLE 2. AWARENESS AND ACCEPTANCE OF LEA AMONG PREGNANT WOMEN IN RURAL AND URBAN AREA

\begin{tabular}{|l|c|c|c|c|}
\hline \multirow{2}{*}{ Views of LEA } & \multicolumn{2}{|c|}{ Rural } & \multicolumn{2}{c|}{ Urban } \\
\cline { 2 - 5 } & $\mathrm{N}=40$ & $\%$ & $\mathrm{~N}=40$ & $\%$ \\
\hline Not aware & 30 & 75 & 15 & 37.5 \\
\hline Aware & 10 & 25 & 25 & 62.5 \\
\hline As pain reliever in labor & 4 & & 18 & \\
\hline $\begin{array}{l}\text { First knowledge from doctor/ } \\
\text { midwife }\end{array}$ & 6 & & 7 & \\
\hline Accept to epidural analgesia & 25 & 62.5 & 35 & 87.5 \\
\hline
\end{tabular}

A majority of the respondents in rural group $30(75 \%)$ were not aware of epidural analgesia. Of the $10(25 \%)$ who were aware, 4 respondents knew it was used to relieve pain labor. While in the urban group, $25(62,5 \%)$ were aware of epidural analgesia with majority respondents knew the use as pain reliever in labor.

Among the respondents in both groups who were aware of this procedure, similar number of participants who claimed that the first knowledge was coming from the doctor or midwife in the hospital was shared. Six and 7 in rural and urban, respectively, which in general constituted $15 \%$ and $17.5 \%$ of respondents in each group. To some point, this low figure has raised a concern on how the dissemination of this procedure among the patients in this hospital has been conducted.

This hospital is a private hospital and does not have a BPJS scheme, Indonesian's government health insurance system, which means that all patients have to incur for the fee, regardless of their socio-economic status. Indeed, for the higher socioeconomic level they tended to have a better option for medical treatment. Yet, only a few patients have received information on LEA procedure. Several studies revealed the influence of socioeconomic status with the healthcare received. Higher socio-economic status may refer to a more additional examination conducted, or the status of health insurance [14]. The perceptions may come from the physicians' side with the tendency to misjudged the patients from lack of role demand or ability [15]. Therefore, this study showed there was a gap of information from the healthcare provider's side in disseminating the option to have a LEA procedure in relieving pain during labor. Indeed, this also revealed a limitation of the current study in trying to dig deeper for more information from the healthcare provider's side of view.

The study also found that majority respondents in both groups would accept epidural analgesia if offered to them 
(62,5\% and $87,5 \%$, rural and urban respectively). It means that socio-economic status does not hinder someone to accept LEA. The majority of women in urban area have awareness in their view higher than in rural area, but the acceptance to receive LEA when it offer to them rural group as well as urban group have the same views because they want to relieve from pain labor. This findings were paralel from Shidaye, et al [16] which majority of the respondents belonged to rural areas and a low socioeconomic stratum of the society.

TABEL 3. THE VIEWS OF PREGNANT WOMEN IN RURAL AND URBAN AREA

\begin{tabular}{|c|c|c|c|c|c|}
\hline \multirow[t]{2}{*}{ Variable } & \multirow{2}{*}{$\begin{array}{c}\text { Pregnant } \\
\text { women } \\
\text { area }\end{array}$} & \multicolumn{2}{|c|}{$\begin{array}{l}\text { Views of } \\
\text { women } \\
\text { with LEA }\end{array}$} & RR & \multirow[t]{2}{*}{$\mathrm{P}$} \\
\hline & & Yes & No & $(95 \%$ C1) & \\
\hline \multirow{2}{*}{ Awareness } & Rural & 10 & 30 & 0,51 & \multirow{2}{*}{$0,002 *$} \\
\hline & Urban & 25 & 15 & $(0,42-0,61)$ & \\
\hline Acceptance & Rural & 25 & 15 & 0,70 & \multirow{2}{*}{$0,001 *$} \\
\hline epidural & Urban & 35 & 5 & $(0,53-0,9)$ & \\
\hline
\end{tabular}

Both group in rural and urban also have awareness and willingness to accept LEA method regarded their views to have no pain delivery process $(p=0,020 ; R R=0,51 ; 95 \% \mathrm{CI}$ : $0,42-0,61$ and $p=0,001 ; R R=0,70 ; C I ; 0,53-0,9)$. Those results are different from Le Ray, et.al [17]. who shows that women with high parity decided to deliver without analgesia, whereas this study has more primigravida.

Almost all of them (98.48\%) irrespective of age, education level, socioeconomic status, were not having any information about labour analgesia. Limitations of our study were hospital based and number of respondents to have labor with LEA technique are still less. To have a final conclusion the study needs in big scale and involve multicentre studies

\section{CONCLUSIONS}

This study shows a lack in awareness of LEA mostly in rural group, and high acceptance in urban group. Given this results the study also have shed some light in the lack of information dissemination from the health care provider in regard to the option of LEA in relieving pain in delivery regardless of the social-economy status. Thus, it is important for the health care provider to offer any means necessary in order to deliver a more comfortable and enjoyable process of delivery.

\section{REFERENCES}

[1] Labor S, Maguire S. The Pain of Labour. Reviews in Pain. 2008;2(2).

[2] Obuna JA, Umeora OU. Perception of Labor Pain and Utilization of Obstetric Analgesia by Igbo Women of Southeast Nigeria. Journal of Obstetric ANaesthesia and Critical Care. 2014;4(1).
[3] Melzack R, Taenzer P, Feldman P, Kinch RA. Labour Is Still Painful After Prepared Childbirth Training. CMA Journal. 1981;125.

[4] Wong CA. Advances in Labor Analgesia. International journal of women's health. 2009;1.

[5] Silva M, Halpern SH. Epidural Analgesia for Labor: Current Techniques. Local and Regional Anesthesia. 2010;3.

[6] Traynor A, Aragon M, Ghosh D, Choi R, Dingmann C, Tran ZV, et al. Obstetric Anesthesia Workforce Survey: A 30year Update. Anesthesia \& Analgesia. 2016;122(6).

[7] Canadian Institute for Health Information. Highlits of 2010-2011 Selected Indicators Describing the Birthing Process in Canada. Canadian Institute for Health Information; 2012.

[8] Kuczowski KM, Chandra S. Maternal Satisfaction with single Dose Spinal Analgesia for Labor Pain in Indonesia: a Landmark Study. Journal of Anesthesia. 2008;22(1).

[9] Poomalar GK, Sameera. Awareness of Labour Analgesia among Antenatal Women in Semi Urban Area. International Journal of Reproduction, Contraception, Obstetrics and Gynecology. 2016;5(8).

[10] Olayemi O, Aimakhu C, Udoh E. Attitudes of patients to obstetric analgesia at the University College Hospital, Ibadan, Nigeria. journal of Obstetry Gynecology. 2003;23(1).

[11] Sheiner E, Sheiner EK, Shoham-Vardi I, Gurman GM, Press F, Mazor M, et al. Predictors of Recommendation and Acceptance of Intrapartum Epidural Analgesia. Anesthesic Analgesia. 2000;90.

[12] Gupta N, Gupta S, Agrawal A, Agrawal S, Diwedi S, Singh J. To Study the Acceptance of Epidural Analgesia for Painless Labor at a Tertiary Care Centre. International Journal of Reproduction, Contraception, Obstetrics and Gynecology. 2014;3(4).

[13] Morr AK, Broscheit J, Blissing S, Bernar T, Dietl J. Einfluss von Faktoren des sozioökonomischen Status auf die Anwendung der Periduralanästhesie subpartal. Z Geburtshilfe Neonatol. 2007;211(01):23-6.

[14] Bernheim SM, Ross JS, Krumbolz HM, Bradley EH. Influence of Patients' Socioeconomic Status on Clinical Management Decisions: A Qualitative Studies. Annals of Family Medicine. 2008;6.

[15] van Ryn M, Burke J. The effect of patient race and socioeconomic status on physicians' perceptions of patients. Social Science \& Medicine. 2000;50(6):813-28.

[16] Shidhaye RV, Galande M, Bangal V, Smita J, Shidhaye R. Awareness and attitude of Indian pregnant women towards labour analgesia. Anaesthesia, Pain \& Intensive Care. 2012;16(2).

[17] Le Ray C, Goffinet F, Palot M, Garel M, Blondel B. Factors Associated with the Choice of Delivery without Epidural Analgesia in Women at Low Risk in France. Birth. 2008;35(3):171-8. 